Acta Crystallographica Section C

Crystal Structure

Communications

ISSN 0108-2701

\section{Effect of substitution on the dimensionality of supramolecular aggregation in dihydrobenzo- pyrazoloquinolines}

\author{
Jaime Portilla, ${ }^{a}$ Jairo Quiroga, ${ }^{a}$ Justo Cobo, ${ }^{b}$ John N. Low ${ }^{c}$ \\ and Christopher Glidewell ${ }^{\text {* }}$
}

${ }^{a}$ Grupo de Investigación de Compuestos Heterocíclicos, Departamento de Química, Universidad de Valle, AA 25360 Cali, Colombia, ${ }^{\mathbf{b}}$ Departamento de Química Inorgánica y Orgánica, Universidad de Jaén, 23071 Jaén, Spain, 'Department of Chemistry, University of Aberdeen, Meston Walk, Old Aberdeen AB24 3UE, Scotland, and ${ }^{\mathbf{d}}$ School of Chemistry, University of St Andrews, Fife KY16 9ST, Scotland

Correspondence e-mail: cg@st-andrews.ac.uk

Received 21 June 2005

Accepted 24 June 2005

Online 23 July 2005

Molecules of 8-methyl-10-phenyl-6,10-dihydro-5 $H$-benzo[ $h]$ pyrazolo[3,4- $b$ ]quinoline, $\mathrm{C}_{21} \mathrm{H}_{17} \mathrm{~N}_{3}$, (I), are linked into cyclic centrosymmetric dimers by means of paired $\mathrm{C}-\mathrm{H} \cdots \mathrm{N}$ hydrogen bonds. In each of 8-methyl-7,10-diphenyl-6,10-dihydro-5H-benzo[ $h]$ pyrazolo[3,4- $b]$ quinoline, $\mathrm{C}_{27} \mathrm{H}_{21} \mathrm{~N}_{3}$, (II), and 8-methyl-7-(4-methylphenyl)-10-phenyl-6,10-dihydro-5 $\mathrm{H}$ benzo[ $h]$ pyrazolo[3,4- $b$ ]quinoline, $\mathrm{C}_{28} \mathrm{H}_{23} \mathrm{~N}_{3}$, (III), the molecules are linked by $\mathrm{C}-\mathrm{H} \cdots \pi$ (arene) hydrogen bonds into sheets, although the detailed construction of the sheets is entirely different in (II) and (III). The molecules of 7-(4methoxyphenyl)-8-methyl-10-phenyl-6,10-dihydro-5H-benzo[h]pyrazolo[3,4- $b$ ]quinoline, $\mathrm{C}_{28} \mathrm{H}_{23} \mathrm{~N}_{3} \mathrm{O}$, (IV), are linked into a complex three-dimensional framework structure by a combination of $\mathrm{C}-\mathrm{H} \cdots \mathrm{N}, \mathrm{C}-\mathrm{H} \cdots \mathrm{O}$ and three independent $\mathrm{C}-\mathrm{H} \cdots \pi$ (arene) hydrogen bonds.

\section{Comment}

Pyrazolo[3,4- $b$ ]quinolines are of interest as possible antiviral and antimalarial agents, and because of their other biological properties, such as parasiticidic, bactericidal, vasodilator, and enzyme-inhibitory activity (Quiroga et al., 2001). We report here the structures of four dihydrobenzopyrazoloquinolines, (I)-(IV) (Figs. 1-4), synthesized by a simple solvent-free cyclocondensation, under microwave irradiation, of 5-amino3-methyl-1-phenylpyrazole and the condensation products derived from 2-tetralone and a range of simple aldehydes. One objective of these structure determinations was the investigation of how the introduction of different simple aryl substituents at position 7 in compounds (II)-(IV) influences the supramolecular aggregation compared with that in the unsubstituted compound, (I). We have recently reported the structures of the isomorphous and isostructural chlorophenyl and bromophenyl analogues, compounds (V) and (VI) (Serrano et al., 2005a,b).

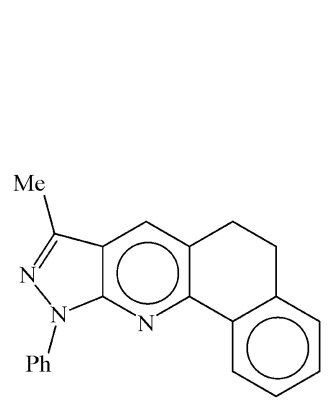

(I)

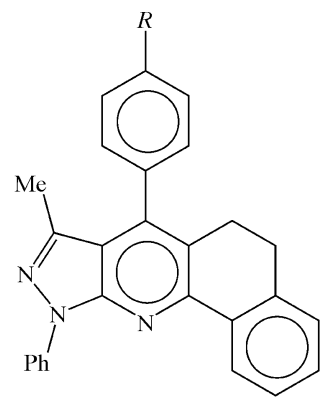

(II) $R=\mathrm{H}$

(III) $R=\mathrm{Me}$

(IV) $R=\mathrm{OMe}$<smiles>[R][X]Cl</smiles>

(VI) $R=\mathrm{Br}$

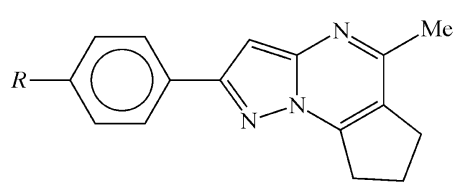

(VII) $R=\mathrm{Me}$

(VIII) $R=\mathrm{Cl}$

(IX) $R=\mathrm{Br}$
In each of compounds (I)-(IV), the bond distances within the fused heterocyclic components are consistent with aromatic delocalization within the pyridine ring, but with strong double-bond fixation in the $\mathrm{C} 8-\mathrm{N} 9$ bond of the pyrazole ring. The other distances and angles present no exceptional features. The non-aromatic carbocyclic ring adopts a nearly ideal screw-boat conformation (Evans \& Boeyens, 1989) in each compound, as shown by the ringpuckering parameters (Cremer \& Pople, 1975), given for the

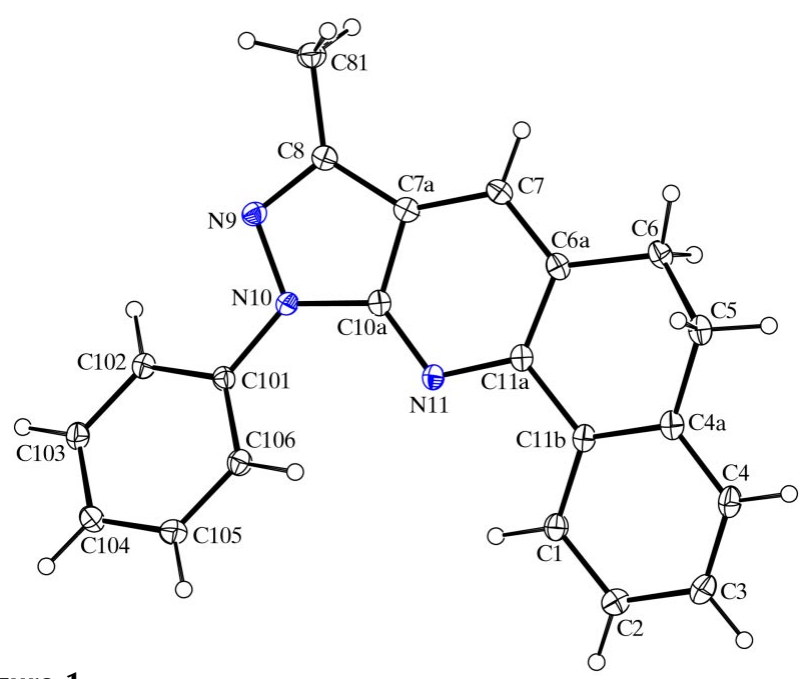

Figure 1

The molecule of (I), showing the atom-labelling scheme. Displacement ellipsoids are drawn at the $30 \%$ probability level. 
atom sequence $\mathrm{C} 4 \mathrm{a}-\mathrm{C} 5-\mathrm{C} 6-\mathrm{C} 6 \mathrm{a}-\mathrm{C} 11 \mathrm{a}-\mathrm{C} 11 \mathrm{~b}$ in Table 1. For a six-membered ring with equal bond lengths throughout, the screw-boat conformation is characterized by $\theta=67.5$ or $112.5^{\circ}$, and $\varphi=(60 k+30)^{\circ}(k=$ integer $)$.

Associated with the screw-boat conformation of the nonaromatic carbocyclic ring, the two aromatic rings linked by the bond $\mathrm{C} 11 \mathrm{a}-\mathrm{C} 11 \mathrm{~b}$ (Figs. 1-4) are not parallel, and they make dihedral angles ranging from $11.11(7)^{\circ}$ in compound (III) to $15.78(7)^{\circ}$ in compound (II) (Table 1). The dihedral angles

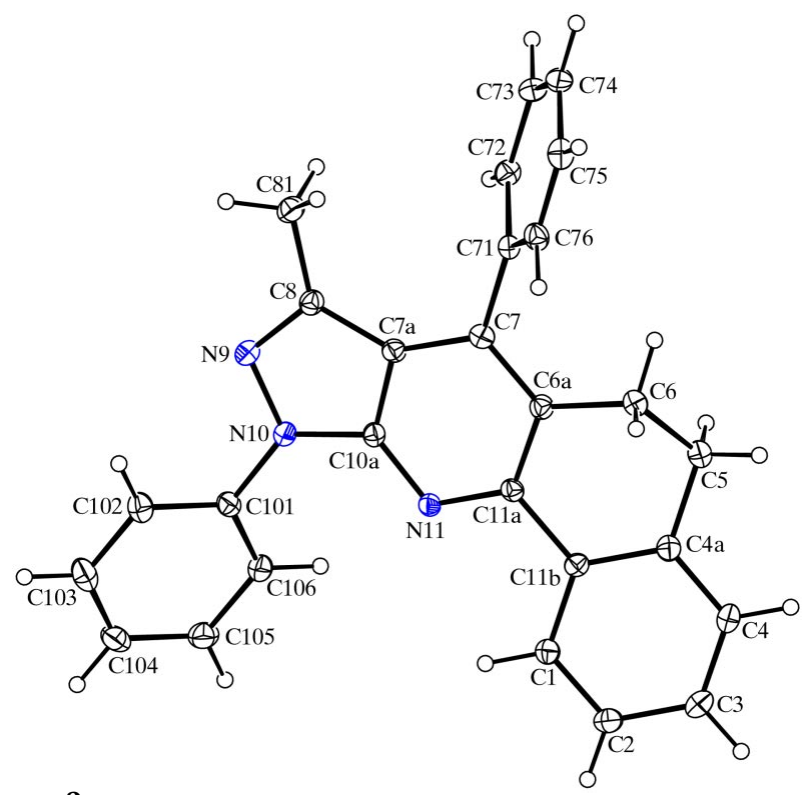

Figure 2

The molecule of (II), showing the atom-labelling scheme. Displacement ellipsoids are drawn at the $30 \%$ probability level.

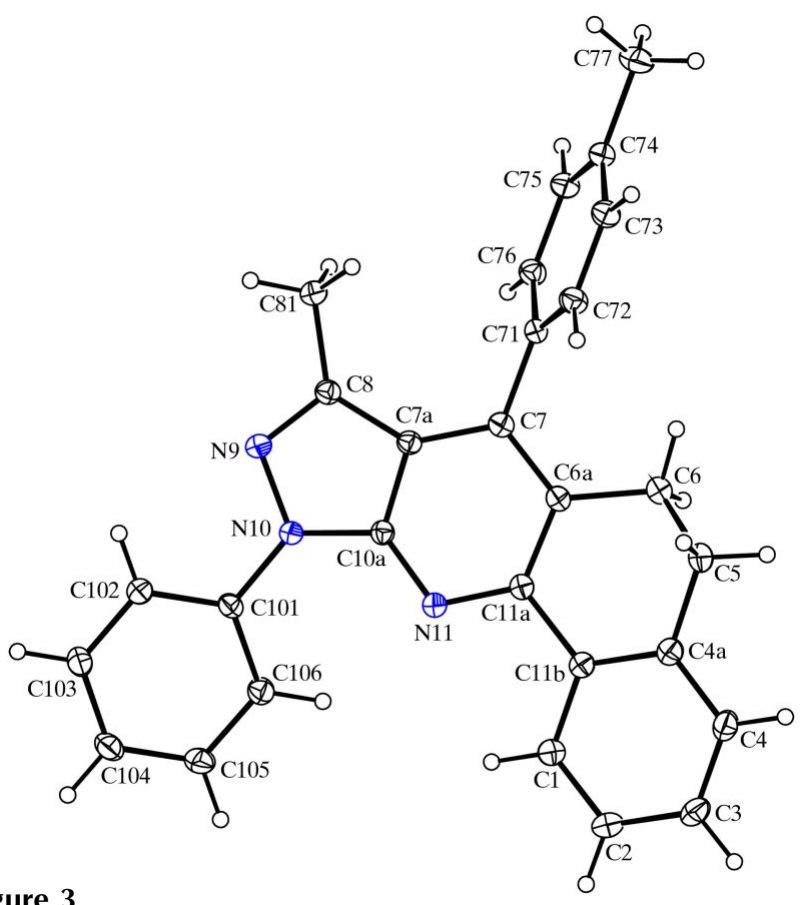

Figure 3

The molecule of (III), showing the atom-labelling scheme. Displacement ellipsoids are drawn at the $30 \%$ probability level. between the pyridine ring and the pendent C71-C76 aryl ring are likewise very similar for compounds (II)-(IV). On the other hand, the dihedral angles between the pyrazole ring and the pendent $\mathrm{C} 101-\mathrm{C} 106$ aryl ring show a rather larger variation. It may be noted here that rings C71-C76 and C101-C106 participate in the hydrogen bonding in each of (II)-(IV), and that the hydrogen bonding may be an important factor in controlling these dihedral angles.

The supramolecular aggregation in compound (I) is extremely simple and involves just one hydrogen bond (Table 2). Atom $\mathrm{C} 5$ in the molecule at $(x, y, z)$ acts as hydrogen-bond donor, via the axial atom $\mathrm{H} 5 A$, to pyrazole atom $\mathrm{N} 9$ in the

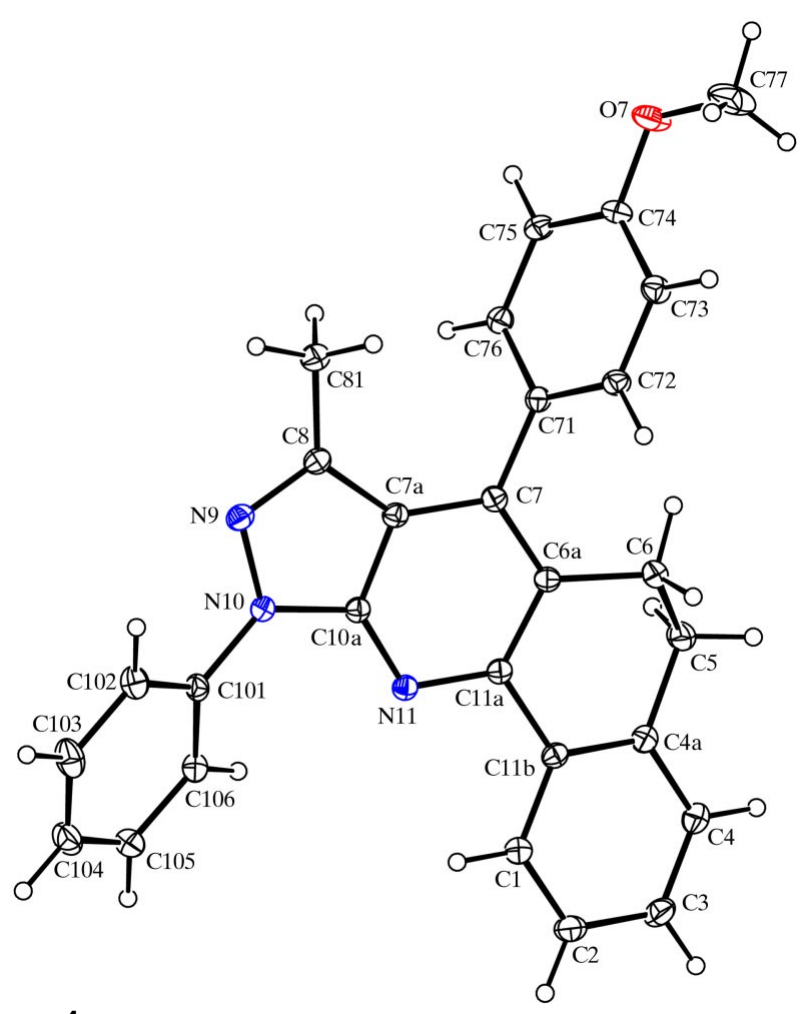

Figure 4

The molecule of (IV), showing the atom-labelling scheme. Displacement ellipsoids are drawn at the $30 \%$ probability level.

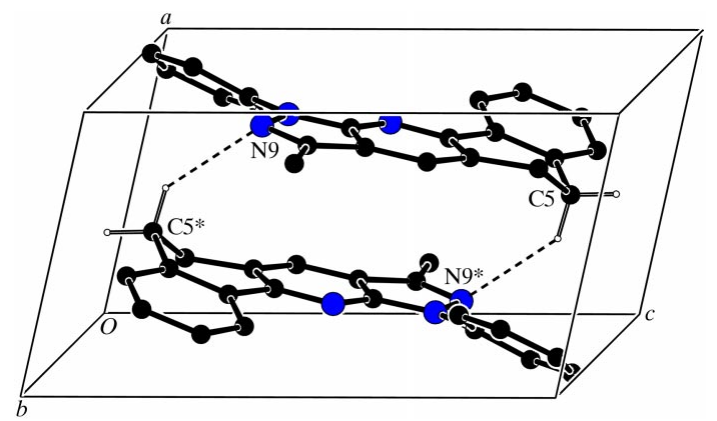

Figure 5

Part of the crystal structure of (I), showing the formation of a centrosymmetric hydrogen-bonded dimer. For the sake of clarity, $\mathrm{H}$ atoms bonded to those $\mathrm{C}$ atoms which are not involved in the motif shown have been omitted. Atoms marked with an asterisk $(*)$ are at the symmetry position $(1-x, 1-y, 1-z)$. 
molecule at $(1-x, 1-y, 1-z)$, so forming a centrosymmetric $R_{2}^{2}(16)$ dimer centred at $\left(\frac{1}{2}, \frac{1}{2}, \frac{1}{2}\right)$ (Fig. 5). The formation of this dimer is reinforced by a $\pi-\pi$ stacking interaction involving the pyridine rings of the two component molecules. These rings are strictly parallel, with an interplanar spacing of 3.450 (2) $\AA$. The ring-centroid separation is $3.729(2) \AA$, corresponding to a nearly ideal ring offset of 1.415 (2) $\AA$. There are no other direction-specific interactions between the molecules; in particular, $\mathrm{C}-\mathrm{H} \cdots \pi$ (arene) hydrogen bonds are absent. Hence, the structure of compound (I) simply consists of isolated centrosymmetric dimers.

By contrast with the structure of (I), there are no $\mathrm{C}-\mathrm{H} \cdots \mathrm{N}$ hydrogen bonds in the structures of either (II) or (III). Instead, the molecules of (II) and (III) are linked into sheets by $\mathrm{C}-\mathrm{H} \cdots \pi$ (arene) hydrogen bonds, a type of interaction absent from the structure of (I). Despite crystallizing in the same space group, namely $P 2_{1} / c$, the formation of the hydrogen-bonded sheets differs considerably between (II) and (III).

In compound (II), the pyridine ring and the pendent C101C106 phenyl ring act as hydrogen-bond acceptors. In the shorter of the two hydrogen bonds (Table 2), atom C73 in the molecule at $(x, y, z)$ acts as donor to the C101-C106 aryl ring in the molecule at $(1-x, 1-y,-z)$, so generating a cyclic
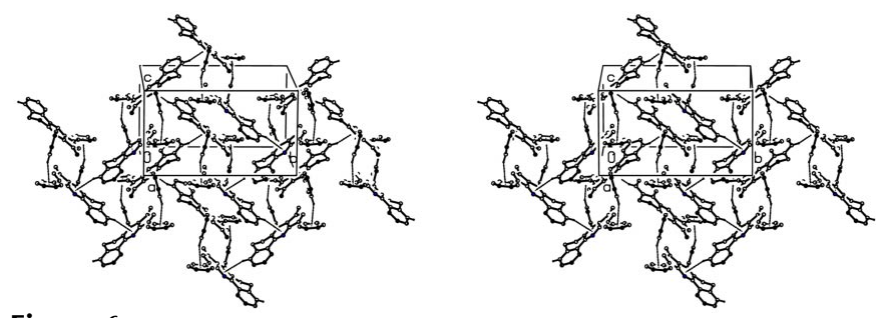

Figure 6

A stereoview of part of the crystal structure of (II), showing the formation of a hydrogen-bonded (100) sheet generated by the combination of an inversion and a glide plane. For the sake of clarity, $\mathrm{H}$ atoms not involved in the motifs shown have been omitted.
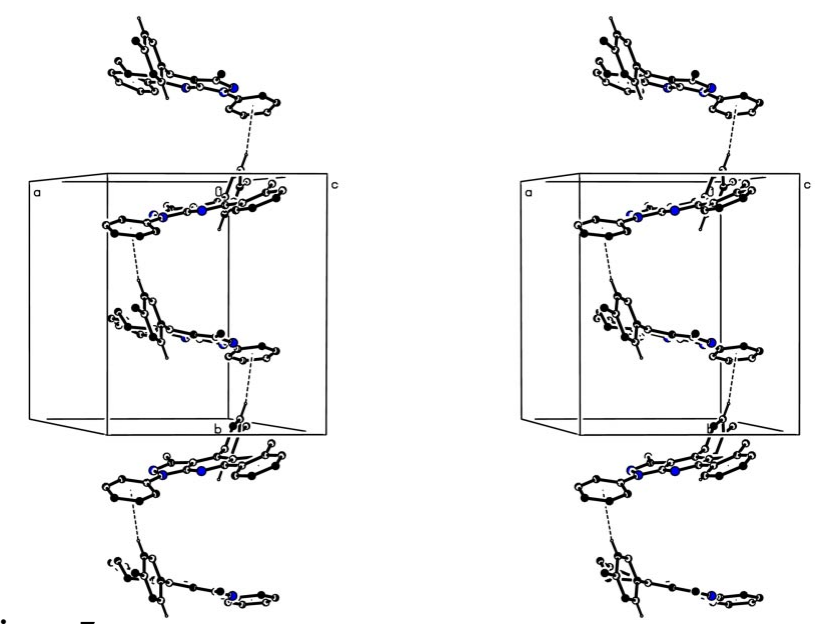

Figure 7

A stereoview of part of the crystal structure of (III), showing the formation of a hydrogen-bonded chain along [010] generated by a $2_{1}$ screw axis. For the sake of clarity, $\mathrm{H}$ atoms not involved in the motif shown have been omitted. and centrosymmetric dimeric motif centred at $\left(\frac{1}{2}, \frac{1}{2}, 0\right)$. The second of the two hydrogen bonds then links this dimer at $\left(\frac{1}{2}, \frac{1}{2}, 0\right)$ to four adjacent dimers. Atoms $\mathrm{C} 4$ in the molecules at $(x, y, z)$ and $(1-x, 1-y,-z)$ act as hydrogen-bond donors to the pyridine rings in the molecules at $\left(x, \frac{1}{2}-y, \frac{1}{2}+z\right)$ and $\left(1-x, \frac{1}{2}+y,-\frac{1}{2}-z\right)$, respectively, which themselves form parts of the dimers centred at $\left(\frac{1}{2}, 0, \frac{1}{2}\right)$ and $\left(\frac{1}{2}, 1,-\frac{1}{2}\right)$, respectively. Similarly, the pyridine rings at $(x, y, z)$ and $(1-x$, $1-y,-z)$ accept hydrogen bonds from the $\mathrm{C} 4$ atoms in the molecules at $\left(x, \frac{1}{2}-y, z-\frac{1}{2}\right)$ and $\left(1-x, \frac{1}{2}+y, \frac{1}{2}-z\right)$, which are themselves components of dimers centred at $\left(\frac{1}{2}, 0,-\frac{1}{2}\right)$ and $\left(\frac{1}{2}, 1, \frac{1}{2}\right)$. Propagation by the space group of these two hydrogen bonds, associated with an inversion and a $c$-glide plane, respectively, then generates a (100) sheet in which large and small rings alternate (Fig. 6).

As in (II), the two-dimensional supramolecular structure of (III) is built from two $\mathrm{C}-\mathrm{H} \cdots \pi$ (arene) hydrogen bonds (Table 2), but now both are associated with translational symmetry operations and there are no directly connected pairs
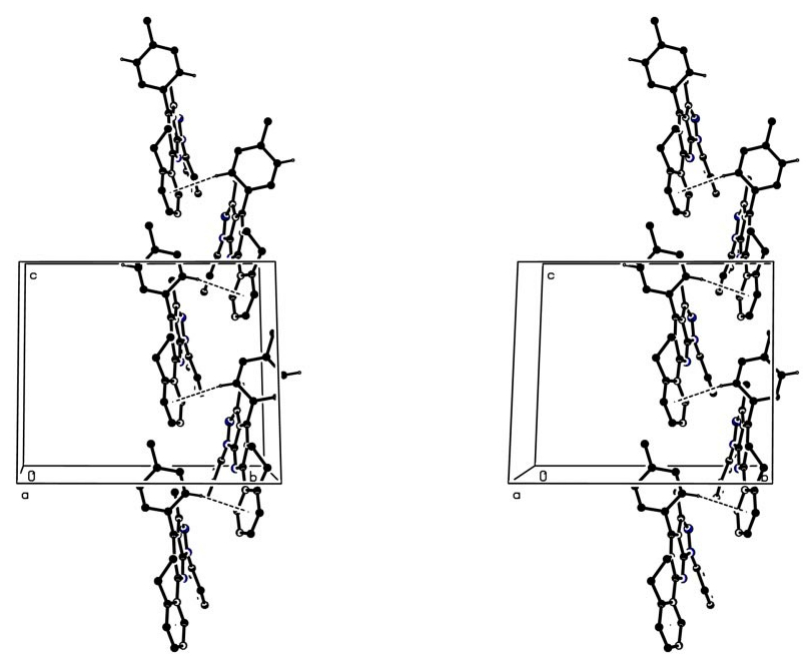

Figure 8

A stereoview of part of the crystal structure of (III), showing the formation of a hydrogen-bonded chain along [001] generated by a glide plane. For the sake of clarity, $\mathrm{H}$ atoms not involved in the motif shown have been omitted.
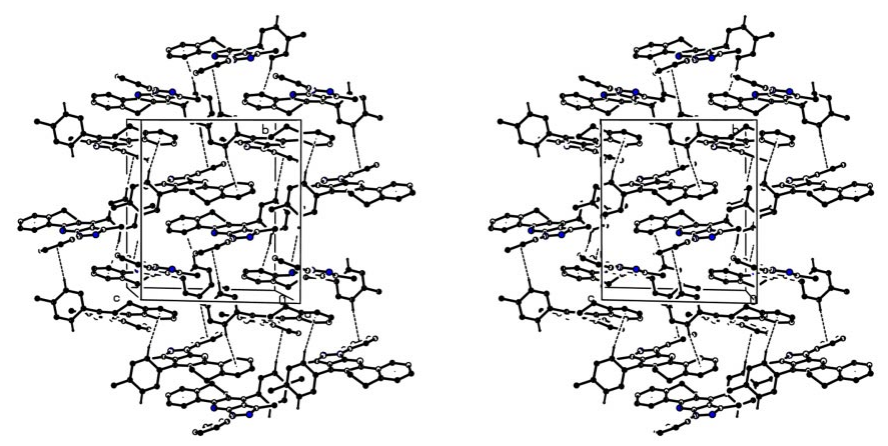

Figure 9

A stereoview of part of the crystal structure of (III), showing the formation of a hydrogen-bonded (100) sheet generated by the combination of the [010] and [001] chains. For the sake of clarity, H atoms not involved in the motifs shown have been omitted. 
of molecules which are related by inversion. Again, unlike the hydrogen bonds in (II), for those in (III) the two donors form parts of the same aryl ring, while the acceptors are the two aryl rings pendent from the fused ring system.

Aryl atom $\mathrm{C} 73$ in the molecule at $(x, y, z)$ acts as hydrogenbond donor to the C101-C106 ring in the molecule at $(1-x$, $y-\frac{1}{2}, \frac{3}{2}-z$ ), thereby forming a chain running parallel to the [010] direction and generated by the $2_{1}$ screw axis along $\left(\frac{1}{2}, y, \frac{3}{4}\right)$ (Fig. 7). In addition, atom $\mathrm{C} 76$ at $(x, y, z)$ acts as hydrogen-bond donor to the $\mathrm{C} 1 / \mathrm{C} 2 / \mathrm{C} 3 / \mathrm{C} 4 / \mathrm{C} 4 \mathrm{a} / \mathrm{C} 11 \mathrm{~b}$ ring in the molecule at $\left(x, \frac{3}{2}-y, \frac{1}{2}+z\right)$, thus producing a chain parallel to the [001] direction and generated by the $c$-glide plane at $y=\frac{3}{4}$ (Fig. 8). The combination of these two chains generates a (100) sheet in the form of a $(4,4)$-net (Fig. 9).

The constitution of compound (IV) differs from those of (I)-(III) in that it provides an additional acceptor of hydrogen
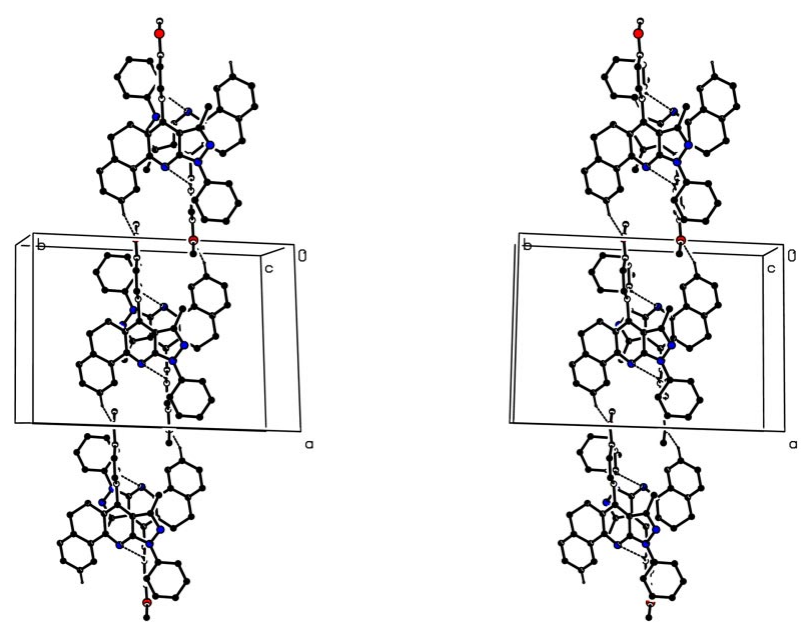

Figure 10

A stereoview of part of the crystal structure of (IV), showing the formation of a chain of edge-fused rings along [101] built from $\mathrm{C}-\mathrm{H} \cdots \mathrm{N}$ and $\mathrm{C}-\mathrm{H} \cdots \mathrm{O}$ hydrogen bonds. For the sake of clarity, $\mathrm{H}$ atoms not involved in the motif shown have been omitted.
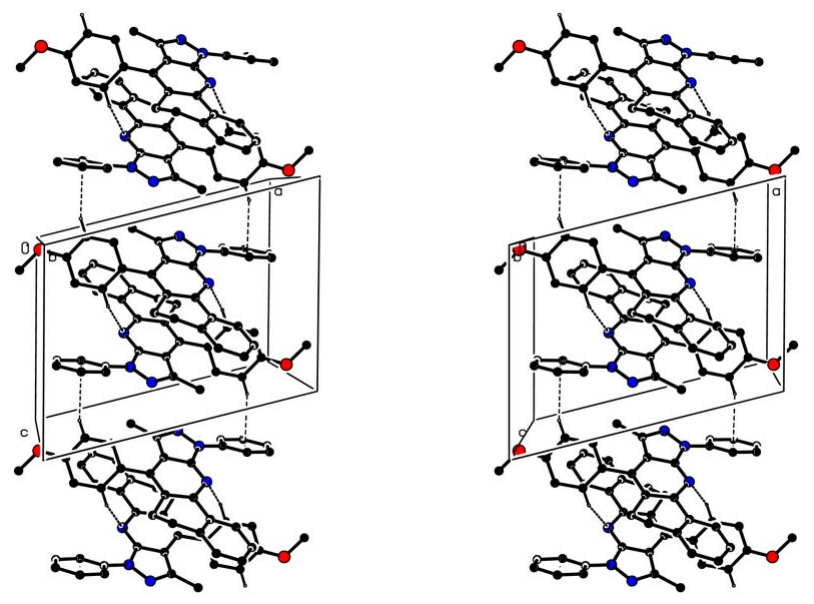

Figure 11

A stereoview of part of the crystal structure of (IV), showing the formation of a chain of edge-fused rings along [001] built from $\mathrm{C}-\mathrm{H} \cdots \mathrm{N}$ and $\mathrm{C}-\mathrm{H} \cdots \pi$ (arene) hydrogen bonds. For the sake of clarity, $\mathrm{H}$ atoms not involved in the motif shown have been omitted. bonds in the $\mathrm{O}$ atom of the methoxy substituent (Fig. 4). In fact, the molecules of (IV) are linked by a combination of $\mathrm{C}-$ $\mathrm{H} \cdots \mathrm{N}, \mathrm{C}-\mathrm{H} \cdots \mathrm{O}$ and $\mathrm{C}-\mathrm{H} \cdots \pi$ (arene) hydrogen bonds (Table 2) into a rather complex three-dimensional framework. The formation of this framework can be analysed very straightforwardly in terms of the component one-dimensional substructures.

In the first such substructure, the $\mathrm{C}-\mathrm{H} \cdots \mathrm{N}$ and $\mathrm{C}-\mathrm{H} \cdots \mathrm{O}$ hydrogen bonds combine to generate a chain of edge-fused rings. Aryl atom $\mathrm{C} 72$ in the molecule at $(x, y, z)$ acts as hydrogen-bond donor to pyridine atom N11 in the molecule at $(1-x, 1-y, 1-z)$, thereby generating a centrosymmetric $R_{2}^{2}(14)$ ring centred at $\left(\frac{1}{2}, \frac{1}{2}, \frac{1}{2}\right)$. In addition, atom C2 at $(x, y, z)$ acts as donor to atom $\mathrm{O} 7$ in the molecule at $(1+x, y, 1+z)$, so generating by translation a $C(12)$ chain running parallel to the [101] direction. The combination of these two hydrogen bonds then generates a chain of edge-fused rings, with $R_{2}^{2}(14)$ rings centred at $\left(n+\frac{1}{2}, \frac{1}{2}, n+\frac{1}{2}\right)(n=$ zero or integer $)$ and $R_{4}^{4}(22)$ rings centred at $\left(n, \frac{1}{2}, n\right)(n=$ zero or integer) (Fig. 10).

The second one-dimensional substructure also takes the form of a chain of edge-fused rings. Aryl atoms C75 in the molecules at $(x, y, z)$ and $(1-x, 1-y, 1-z)$, which form the $R_{2}^{2}(14)$ dimer centred at $\left(\frac{1}{2}, \frac{1}{2}, \frac{1}{2}\right)$, act as hydrogen-bond donors to the $\mathrm{C} 101-\mathrm{C} 106$ rings in the molecules at $(1-x, 1-y,-z)$ and $(x, y, 1+z)$, respectively, which themselves form part of the $R_{2}^{2}(14)$ dimers centred at $\left(\frac{1}{2}, \frac{1}{2},-\frac{1}{2}\right)$ and $\left(\frac{1}{2}, \frac{1}{2}, \frac{3}{2}\right)$, respectively, so forming a chain of edge-fused centrosymmetric rings running parallel to the [001] direction (Fig. 11).

In addition to this [001] chain of edge-fused rings generated by inversion, there is a second substructure running parallel to [001] in the form of a simple chain generated by a $c$-glide plane. Aryl atom $\mathrm{C} 4$ in the molecule at $(x, y, z)$ acts as hydrogen-bond donor to the pyridine ring in the molecule at $\left(x, \frac{3}{2}-y, \frac{1}{2}+z\right)$, producing an [001] chain generated by the $c$ glide plane at $y=\frac{3}{4}$ (Fig. 12).

In the final substructure, atom $\mathrm{C} 103$ in the molecule at $(x, y$, $z$ ) acts as hydrogen-bond donor to the pendent C71-C76 aryl

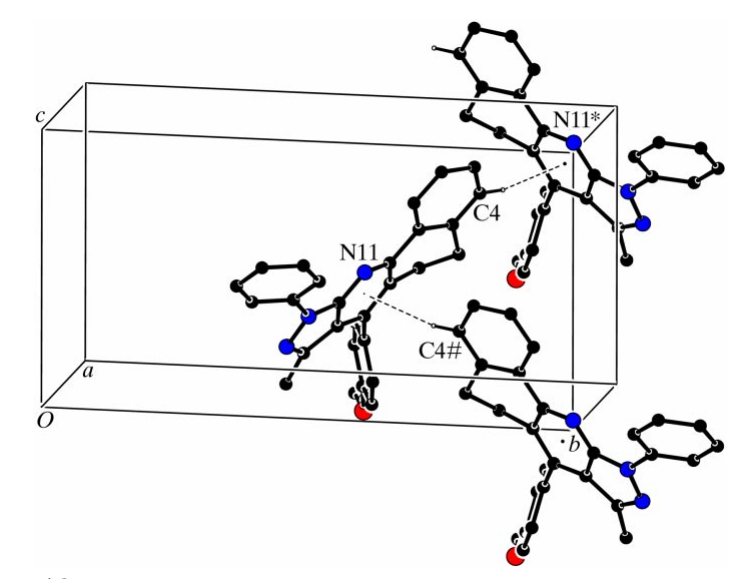

Figure 12

Part of the crystal structure of (IV), showing the formation of a simple [001] chain built from $\mathrm{C}-\mathrm{H} \cdots \pi($ arene $)$ hydrogen bonds. For the sake of clarity, $\mathrm{H}$ atoms not involved in the motif shown have been omitted. Atoms marked with an asterisk (*) or a hash (\#) are at the symmetry positions $\left(x, \frac{3}{2}-y, \frac{1}{2}+z\right)$ and $\left(x, \frac{3}{2}-y, z-\frac{1}{2}\right)$, respectively. 
ring in the molecule at $\left(1-x, y-\frac{1}{2}, \frac{1}{2}-z\right)$, so forming a chain running parallel to the [010] direction and generated by the $2_{1}$ screw axis along $\left(\frac{1}{2}, y, \frac{1}{4}\right)$ (Fig. 13).

The combination of the chains along [010], [001] and [101] suffices to link all of the molecules into a single threedimensional framework, the complexity of which arises largely from the occurrence in the structure of five independent hydrogen bonds (Table 2).

We briefly compare the supramolecular structures of compounds (I)-(IV) reported here with those of the pair of compounds, (V) and (VI) (see scheme), containing 4-halogenophenyl substituents, where the molecular skeleton is a simple positional isomer of the skeleton in compounds (I)(IV), and which are themseleves strictly isostructural in space group $P \overline{1}$, as reported recently (Serrano et al., 2005a,b). In these analogues, the molecules are linked by $\mathrm{C}-\mathrm{H} \cdots \pi$ (arene) hydrogen bonds into chains of edge-fused rings. Hence, within this rather compact group of compounds, viz. (I)-(VI), the supramolecular aggregation ranges from finite (zero-dimensional) in compound (I), via one-dimensional in compounds (V) and (VI) and two-dimensional in compounds (II) and (III), to three-dimensional in compound (IV).

The differences between the 4-methylphenyl compound, (III), and the 4-chlorophenyl compound, (V), in terms of both their space groups, namely $P 2_{1} / c$ for (III) as opposed to $P \overline{1}$ for $(\mathrm{V})$, and their supramolecular dimensionality, namely twodimensional for (III) as opposed to one-dimensional for (V), is

\section{Figure 13}

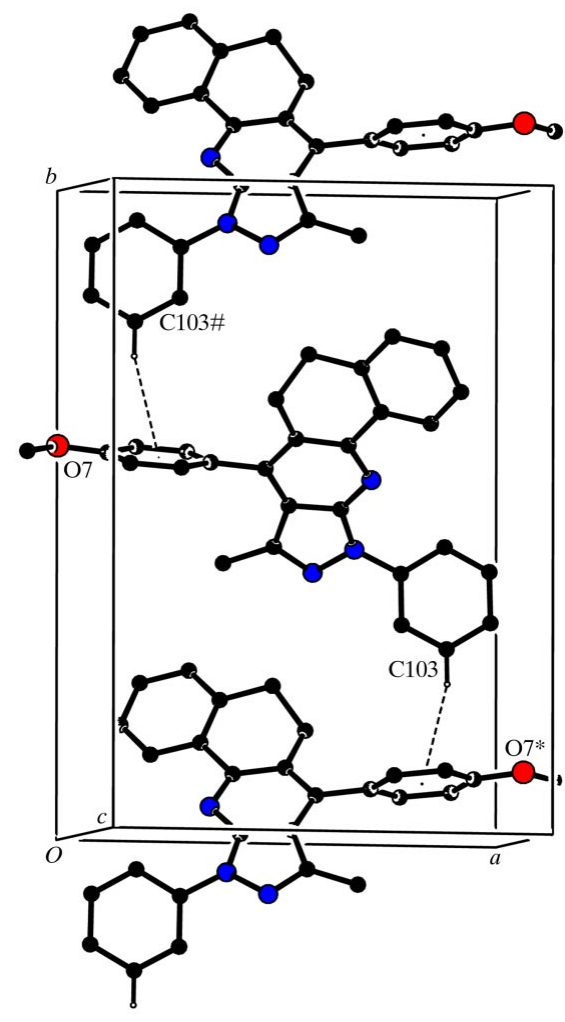

Part of the crystal structure of (IV), showing the formation of a simple [010] chain built from $\mathrm{C}-\mathrm{H} \cdots \pi($ arene) hydrogen bonds. For the sake of clarity, $\mathrm{H}$ atoms not involved in the motif shown have been omitted. Atoms marked with an asterisk (*) or a hash (\#) are at the symmetry positions $\left(1-x, y-\frac{1}{2}, \frac{1}{2}-z\right)$ and $\left(1-x, \frac{1}{2}+y, \frac{1}{2}-z\right)$, respectively.

unexpected, as methyl and chloro substituents on aryl rings are generally effectively isosteric. This is well illustrated, for example, by the related series of fused heterocycles (VII)(IX) (see scheme) containing, respectively, 4-methylphenyl, 4-chlorophenyl and 4-bromophenyl substituents, which are all isomorphous and strictly isostructural (Portilla et al., 2005).

\section{Experimental}

For the preparation of the title compounds, equimolar quantities of 5-amino-3-methyl-1-phenylpyrazole $(1.0 \mathrm{mmol})$ and the corresponding methylene derivative (from 2-tetralone and the appropriate aldehyde) (1.0 mmol) were placed in open Pyrex glass vessels and irradiated in a domestic microwave oven for 3-5 min at $600 \mathrm{~W}$. The reaction mixture was extracted with ethanol and the extract was evaporated. The solid residues were recrystallized from dimethylformamide to give crystals suitable for single-crystal X-ray diffraction. Analysis for (I): yellow crystals (m.p. 439-440 K, yield 60\%), MS $(30 \mathrm{eV}) \mathrm{m} / \mathrm{z}(\%)=311\left(100, M^{+}\right), 296(7)$; for (II): yellow crystals (m.p. 494-495 K, yield 78\%), MS (30 eV) $\mathrm{m} / z(\%)=388(36), 387$ $\left(100, M^{+}\right), 372$ (6); for (III): yellow crystals (m.p. 484-485 K, yield $75 \%)$, MS $(30 \mathrm{eV}) \mathrm{m} / z(\%)=402(36), 401\left(100, M^{+}\right), 386(6)$; for (IV): pale-brown crystals (m.p. $484-485 \mathrm{~K}$, yield $60 \%)$, MS $(30 \mathrm{eV})$ $m / z(\%)=418(33), 417\left(100, M^{+}\right), 402(6)$.

\section{Compound (I)}

\section{Crystal data}

$$
\begin{aligned}
& \mathrm{C}_{21} \mathrm{H}_{17} \mathrm{~N}_{3} \\
& M_{r}=311.38 \\
& \text { Triclinic, } P \overline{1} \\
& a=7.0870(2) \AA \\
& b=10.1321(4) \AA \\
& c=11.7977(5) \AA \\
& \alpha=87.501(2)^{\circ} \\
& \beta=73.171(3)^{\circ} \\
& \gamma=74.828(2)^{\circ} \\
& V=782.13(5) \AA^{3}
\end{aligned}
$$

Data collection

Bruker-Nonius KappaCCD areadetector diffractometer $\varphi$ and $\omega$ scans

Absorption correction: multi-scan (SADABS; Sheldrick, 2003)

$T_{\min }=0.954, T_{\max }=0.992$

15116 measured reflections

\section{Refinement}

Refinement on $F^{2}$

$R\left[F^{2}>2 \sigma\left(F^{2}\right)\right]=0.043$

$w R\left(F^{2}\right)=0.114$

$S=1.04$

3576 reflections

218 parameters

$\mathrm{H}$-atom parameters constrained

\section{Compound (II)}

$$
\begin{aligned}
& \text { Crystal data } \\
& \mathrm{C}_{27} \mathrm{H}_{21} \mathrm{~N}_{3} \\
& M_{r}=387.47 \\
& \text { Monoclinic, } P 2_{1} / c \\
& a=11.5561(4) \AA \\
& b=17.6751(7) \AA \\
& c=9.8469(3) \AA \\
& \beta=98.599(2)^{\circ} \\
& V=1988.67(12) \AA^{3} \\
& Z=4
\end{aligned}
$$

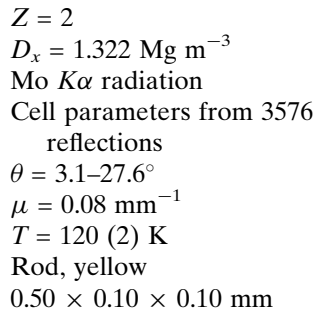

3576 independent reflections 2810 reflections with $I>2 \sigma(I)$ $R_{\text {int }}=0.039$

$\theta_{\text {max }}=27.6^{\circ}$

$h=-8 \rightarrow 9$

$k=-12 \rightarrow 13$

$l=-15 \rightarrow 15$

$$
\begin{gathered}
w=1 /\left[\sigma^{2}\left(F_{\mathrm{o}}^{2}\right)+(0.0601 P)^{2}\right. \\
+0.1501 P] \\
\text { where } P=\left(F_{\mathrm{o}}^{2}+2 F_{\mathrm{c}}^{2}\right) / 3 \\
(\Delta / \sigma)_{\max }<0.001 \\
\Delta \rho_{\max }=0.23 \mathrm{e} \AA^{-3} \\
\Delta \rho_{\min }=-0.28 \mathrm{e} \AA^{-3}
\end{gathered}
$$




\section{organic compounds}

\section{Data collection}

Bruker-Nonius KappaCCD areadetector diffractometer

$\varphi$ and $\omega$ scans

Absorption correction: multi-scan (SADABS; Sheldrick, 2003)

$T_{\min }=0.973, T_{\max }=0.985$

26788 measured reflections

\section{Refinement}

Refinement on $F^{2}$

$R\left[F^{2}>2 \sigma\left(F^{2}\right)\right]=0.048$

$w R\left(F^{2}\right)=0.126$

$S=1.08$

4539 reflections

272 parameters

$\mathrm{H}$-atom parameters constrained

\section{Compound (III)}

\section{Crystal data}

$\mathrm{C}_{28} \mathrm{H}_{23} \mathrm{~N}_{3}$

$M_{r}=401.49$

Monoclinic, $P 2_{1} / c$

$a=12.0313(3) \AA$

$b=14.3347$ (4) $\AA$

$c=12.7956(3) \AA$

$\beta=109.3092(14)^{\circ}$

$V=2082.66(9) \AA^{3}$

$Z=4$

\section{Data collection}

Bruker-Nonius KappaCCD areadetector diffractometer

$\varphi$ and $\omega$ scans

Absorption correction: multi-scan (SADABS; Sheldrick, 2003)

$T_{\min }=0.956, T_{\max }=0.989$

38247 measured reflections

\section{Refinement}

Refinement on $F^{2}$

$R\left[F^{2}>2 \sigma\left(F^{2}\right)\right]=0.050$

$w R\left(F^{2}\right)=0.129$

$S=1.04$

4778 reflections

282 parameters

$\mathrm{H}$-atom parameters constrained

\section{Compound (IV)}

\section{Crystal data}

$\mathrm{C}_{28} \mathrm{H}_{23} \mathrm{~N}_{3} \mathrm{O}$

$M_{r}=417.49$

Monoclinic, $P 2_{1} / c$

$a=12.9148(3) \AA$

$b=17.5938(5) \AA$

$c=9.8192(2) \AA$

$\beta=104.3370(17)^{\circ}$

$V=2161.64(9) \AA^{3}$

$Z=4$

\section{Data collection}

Bruker-Nonius KappaCCD areadetector diffractometer

$\varphi$ and $\omega$ scans

Absorption correction: multi-scan (SADABS; Sheldrick, 2003)

$T_{\min }=0.974, T_{\max }=0.996$

35681 measured reflections
4539 independent reflections 3236 reflections with $I>2 \sigma(I)$

$R_{\text {int }}=0.053$

$\theta_{\text {max }}=27.5^{\circ}$

$h=-15 \rightarrow 13$

$k=-22 \rightarrow 22$

$l=-12 \rightarrow 12$

$$
\begin{gathered}
w=1 /\left[\sigma^{2}\left(F_{\mathrm{o}}{ }^{2}\right)+(0.0639 P)^{2}\right. \\
\quad+0.3388 P] \\
\text { where } P=\left(F_{\mathrm{o}}{ }^{2}+2 F_{\mathrm{c}}{ }^{2}\right) / 3 \\
(\Delta / \sigma)_{\max }<0.001 \\
\Delta \rho_{\max }=0.28 \mathrm{e} \AA^{-3} \\
\Delta \rho_{\min }=-0.29 \AA^{-3}
\end{gathered}
$$

\author{
$D_{x}=1.280 \mathrm{Mg} \mathrm{m}^{-3}$ \\ Mo $K \alpha$ radiation \\ Cell parameters from 4778 \\ reflections \\ $\theta=3.2-27.5^{\circ}$ \\ $\mu=0.08 \mathrm{~mm}^{-1}$ \\ $T=120(2) \mathrm{K}$ \\ Lath, yellow \\ $0.66 \times 0.42 \times 0.14 \mathrm{~mm}$
}

4778 independent reflections 3416 reflections with $I>2 \sigma(I)$ $R_{\text {int }}=0.059$

$\theta_{\text {max }}=27.5^{\circ}$

$h=-15 \rightarrow 15$

$k=-18 \rightarrow 18$

$l=-16 \rightarrow 16$

$$
\begin{gathered}
w=1 /\left[\sigma^{2}\left(F_{\mathrm{o}}{ }^{2}\right)+(0.066 P)^{2}\right. \\
+0.5056 P] \\
\text { where } P=\left(F_{\mathrm{o}}{ }^{2}+2 F_{\mathrm{c}}{ }^{2}\right) / 3 \\
(\Delta / \sigma)_{\max }<0.001 \\
\Delta \rho_{\max }=0.41 \mathrm{e}^{-3} \\
\Delta \rho_{\min }=-0.31 \mathrm{e}^{-3}
\end{gathered}
$$

$$
\begin{aligned}
& D_{x}=1.283 \mathrm{Mg} \mathrm{m}^{-3} \\
& \text { Mo } K \alpha \text { radiation } \\
& \text { Cell parameters from } 4963 \\
& \quad \text { reflections } \\
& \theta=3.3-27.5^{\circ} \\
& \mu=0.08 \mathrm{~mm}^{-1} \\
& T=120(2) \mathrm{K} \\
& \text { Plate, pale brown } \\
& 0.50 \times 0.20 \times 0.05 \mathrm{~mm}
\end{aligned}
$$

4963 independent reflections 3449 reflections with $I>2 \sigma(I)$

$R_{\text {int }}=0.062$

$\theta_{\max }=27.5^{\circ}$

$h=-16 \rightarrow 16$

$k=-22 \rightarrow 22$

\begin{tabular}{|c|c|c|c|c|c|}
\hline & $D-\mathrm{H} \cdots A$ & $D-\mathrm{H}$ & $\mathrm{H} \cdots A$ & $D \cdots A$ & $D-\mathrm{H} \cdots A$ \\
\hline (I) & $\mathrm{C} 5-\mathrm{H} 5 A \cdots \mathrm{N} 9^{\mathrm{i}}$ & 0.99 & 2.60 & $3.4070(18)$ & 139 \\
\hline \multirow[t]{2}{*}{ (II) } & $\mathrm{C} 4-\mathrm{H} 4 \cdots C g 1^{\mathrm{ii}}$ & 0.95 & 2.82 & 3.7461 (17) & 164 \\
\hline & $\mathrm{C} 73-\mathrm{H} 73 \cdots C g 2^{\mathrm{iii}}$ & 0.95 & 2.62 & 3.4852 (17) & 152 \\
\hline \multirow[t]{2}{*}{ (III) } & $\mathrm{C} 73-\mathrm{H} 73 \cdots \mathrm{Cg} 2^{\mathrm{iv}}$ & 0.95 & 2.96 & $3.8991(18)$ & 168 \\
\hline & $\mathrm{C} 76-\mathrm{H} 76 \cdots \mathrm{Cg}^{\mathrm{v}}$ & 0.95 & 2.90 & $3.8349(17)$ & 168 \\
\hline \multirow[t]{5}{*}{ (IV) } & $\mathrm{C} 2-\mathrm{H} 2 \cdots \mathrm{O} 7^{\mathrm{vi}}$ & 0.95 & 2.53 & $3.3422(18)$ & 144 \\
\hline & $\mathrm{C} 72-\mathrm{H} 72 \cdots \mathrm{N} 11^{\mathrm{i}}$ & 0.95 & 2.60 & $3.3952(17)$ & 142 \\
\hline & $\mathrm{C} 4-\mathrm{H} 4 \cdots C g 1^{\mathrm{v}}$ & 0.95 & 2.84 & $3.7766(17)$ & 168 \\
\hline & $\mathrm{C} 75-\mathrm{H} 75 \cdots C g 2^{\mathrm{iii}}$ & 0.95 & 2.67 & $3.5605(15)$ & 157 \\
\hline & $\mathrm{C} 103-\mathrm{H} 103 \cdots C g 4^{\mathrm{vii}}$ & 0.95 & 2.85 & 3.7417 (19) & 157 \\
\hline
\end{tabular}

$l=-12 \rightarrow 11$

\section{Refinement}

Refinement on $F^{2}$

$R\left[F^{2}>2 \sigma\left(F^{2}\right)\right]=0.044$

$w R\left(F^{2}\right)=0.112$

$S=1.04$

4963 reflections

291 parameters

$\mathrm{H}$-atom parameters constrained

$$
\begin{aligned}
& w=1 /\left[\sigma^{2}\left(F_{\mathrm{o}}^{2}\right)+(0.0534 P)^{2}\right. \\
& \quad+0.4296 P] \\
& \text { where } P=\left(F_{\mathrm{o}}^{2}+2 F_{\mathrm{c}}^{2}\right) / 3 \\
& (\Delta / \sigma)_{\max }=0.001 \\
& \Delta \rho_{\max }=0.21 \mathrm{e} \AA^{-3} \\
& \Delta \rho_{\min }=-0.27 \AA^{-3}
\end{aligned}
$$

\section{Table 1}

Ring-puckering parameters and selected dihedral angles $\left(\AA{ }^{\circ}\right)$ for compounds (I)-(IV).

The ring-puckering parameters for the non-aromatic carbocyclic ring are calculated for the atom sequence $\mathrm{C} 4 \mathrm{a}-\mathrm{C} 5-\mathrm{C} 6-\mathrm{C} 6 \mathrm{a}-\mathrm{C} 11 \mathrm{a}-\mathrm{C} 11 \mathrm{~b}$.

\begin{tabular}{lllll}
\hline Parameter & (I) & (II) & (III) & (IV) \\
\hline$Q$ & $0.423(2)$ & $0.461(2)$ & $0.460(2)$ & $0.450(2)$ \\
$\theta$ & $63.9(2)$ & $115.4(2)$ & $61.5(2)$ & $115.5(2)$ \\
$\varphi$ & $89.6(2)$ & $274.1(2)$ & $96.6(2)$ & $271.6(2)$ \\
(C1-C4/C4a/C11b)/pyridine & $13.84(7)$ & $15.78(7)$ & $11.11(7)$ & $14.79(7)$ \\
(C71-C76)/pyridine & & $63.45(7)$ & $65.27(7)$ & $60.88(7)$ \\
(C101-C106)/pyrazole & $26.21(7)$ & $33.16(8)$ & $18.56(8)$ & $30.30(4)$ \\
\hline
\end{tabular}

Table 2

Hydrogen-bond geometry $\left(\AA{ }^{\circ},{ }^{\circ}\right)$ for compounds (I)-(IV).

$C g 1-C g 4$ are the centroids of rings $\mathrm{N} 11 / \mathrm{C} 10 \mathrm{a} / \mathrm{C} 7 \mathrm{a} / \mathrm{C} 7 / \mathrm{C} 6 \mathrm{a} / \mathrm{C} 11 \mathrm{a}, \mathrm{C} 101-\mathrm{C} 106$, $\mathrm{C} 1-\mathrm{C} 4 / \mathrm{C} 4 \mathrm{a} / \mathrm{C} 11 \mathrm{a}$ and $\mathrm{C} 71-\mathrm{C} 76$, respectively.

Symmetry codes: (i) $1-x, 1-y, 1-z$; (ii) $x, \frac{1}{2}-y, \frac{1}{2}+z$; (iii) $1-x, 1-y,-z$; (iv) $1-x, y-\frac{1}{2}, \frac{3}{2}-z$; (v) $x, \frac{3}{2}-y, \frac{1}{2}+z$; (vi) $1+x, y, 1+z$; (vii) $1-x, y-\frac{1}{2}, \frac{1}{2}-z$.

Crystals of compound (I) are triclinic; space group $P \overline{1}$ was selected and then confirmed by the successful structure analysis. For each of compounds (II)-(IV), the space group $P 2_{1} / c$ was uniquely assigned from the systematic absences. All $\mathrm{H}$ atoms were located from difference maps and then treated as riding atoms, with $\mathrm{C}-\mathrm{H}$ distances of 0.95 (aromatic), $0.98\left(\mathrm{CH}_{3}\right)$ or $0.99 \AA\left(\mathrm{CH}_{2}\right)$, and with $U_{\text {iso }}(\mathrm{H})=1.2 U_{\text {eq }}(\mathrm{C})$, or $1.5 U_{\text {eq }}(\mathrm{C})$ for the methyl groups. The crystals of compound (III) were very fragile, and attempts to cut small fragments from larger crystals resulted in shattering.

For all compounds, data collection: COLLECT (Hooft, 1999); cell refinement: DENZO (Otwinowski \& Minor, 1997) and COLLECT; data reduction: $D E N Z O$ and COLLECT; program(s) used to solve structure: OSCAIL (McArdle, 2003) and SHELXS97 (Sheldrick, 1997); program(s) used to refine structure: OSCAIL and SHELXL97 (Sheldrick, 1997); molecular graphics: PLATON (Spek, 2003); software used to prepare material for publication: SHELXL97 and PRPKAPPA (Ferguson, 1999).

The X-ray data were collected at the EPSRC X-ray Crystallographic Service, University of Southampton. JC thanks the Consejería de Innovación, Ciencia y Empresa (Junta de 
Andalucía, Spain) and the Universidad de Jaén for financial support. JQ and JP thank COLCIENCIAS and UNIVALLE (Universidad del Valle, Colombia) for financial support.

Supplementary data for this paper are available from the IUCr electronic archives (Reference: SK1854). Services for accessing these data are described at the back of the journal.

\section{References}

Cremer, D. \& Pople, J. A. (1975). J. Am. Chem. Soc. 97, 1354-1358. Evans, D. G. \& Boeyens, J. C. A. (1989). Acta Cryst. B45, 581-590. Ferguson, G. (1999). PRPKAPPA. University of Guelph, Canada. Hooft, R. W. W. (1999). COLLECT. Nonius BV, Delft, The Netherlands.
McArdle, P. (2003). OSCAIL for Windows. Version 10. Crystallography Centre, Chemistry Department, NUI Galway, Ireland.

Otwinowski, Z. \& Minor, W. (1997). Methods in Enzymology, Vol. 276, Macromolecular Crystallography, Part A, edited by C. W. Carter Jr \& R. M. Sweet, pp. 307-326. New York: Academic Press.

Portilla, J., Quiroga, J., Cobo, J., Low, J. N. \& Glidewell, C. (2005). Acta Cryst. C61, o452-0456.

Quiroga, J., Mejía, D., Insuasty, B., Abonia, R., Nogueras, M., Sánchez, A., Cobo, J. \& Low, J. N. (2001). Tetrahedron, 57, 6947-6953.

Serrano, H., Quiroga, J., Cobo, J., Low, J. N. \& Glidewell, C. (2005a). Acta Cryst. E61, o1058-o1060.

Serrano, H., Quiroga, J., Cobo, J., Low, J. N. \& Glidewell, C. (2005b). Acta Cryst. E61, o1702-o1703.

Sheldrick, G. M. (1997). SHELXS97 and SHELXL97. University of Göttingen, Germany.

Sheldrick, G. M. (2003). SADABS. Version 2.10. University of Göttingen, Germany.

Spek, A. L. (2003). J. Appl. Cryst. 36, 7-13. 